ISSN 1980-5098

\title{
PRODUTIVIDADE DE MINICEPAS E ENRAIZAMENTO DE MINIESTACAS DE HÍBRIDOS DE Eucalyptus globulus LABILL. EM RESPOSTA A NITROGÊNIO
}

\author{
PRODUCTIVITY OF MINISTUMPS AND ROOTING OF MINICUTTINGS OF HYBRIDS OF \\ Eucalyptus globulus LABILL IN RESPONSE TO NITROGEN
}

\author{
Alex Ferreira de Freitas ${ }^{1}$ Haroldo Nogueira de Paiva ${ }^{2}$ Aloisio Xavier ${ }^{3}$ Júlio César Lima Neves ${ }^{4}$
}

\begin{abstract}
RESUMO
O objetivo deste trabalho foi avaliar a produtividade de minicepas e o enraizamento de miniestacas de clones híbridos de Eucalyptus globulus em resposta a concentrações de nitrogênio em fertirrigação de minijardim clonal. Para isso, utilizaram-se cinco clones, sendo: dois clones de Eucalyptus urophylla $\mathrm{x}$ Eucalyptus globulus (C-04 e C-16); dois clones de Eucalyptus grandis x Eucalyptus globulus (C-26 e C-30) e um clone de Eucalyptus urophylla x Eucalyptus grandis (1213) como referência. Foram testadas cinco concentrações de $\mathrm{N}\left(36,72,109,164\right.$ e $\left.218 \mathrm{mg} \mathrm{L}^{-1}\right)$ no arranjo de parcelas subdivididas com três repetições, em delineamento estatístico de blocos ao acaso. Seis meses após a implantação do minijardim, utilizando solução nutritiva padrão, em sistema de fertirrigação, aplicaram-se os tratamentos por 30 dias, quando iniciaram-se as coletas das miniestacas semanalmente e o estaqueamento a cada 15 dias, durante 90 dias. Avaliou-se a sobrevivência e produtividade das minicepas e a sobrevivência das miniestacas, porcentagem de enraizamento e porcentagem de miniestacas com raízes visíveis na extremidade inferior do tubete. Verificou-se a existência de efeito significativo das concentrações de nitrogênio para produtividade mensal das minicepas dos clones C-16 (169,05 mg L-1), C-26 (146,67 $\left.\mathrm{mg} \mathrm{L}^{-1}\right)$ e para C-04 e 1213, efeito linear positivo. Entretanto, não foi observado efeito significativo das concentrações para a percentagem de miniestacas com raízes visíveis na extremidade inferior do tubete, enraizamento e sobrevivência das miniestacas aos trinta dias em casa de vegetação.
\end{abstract}

Palavras-chave: minijardim clonal; nutrição mineral; propagação vegetativa.

\section{ABSTRACT}

The aim of this study was to evaluate the productivity of ministumps and the rooting of minicuttings from hybrid clones of Eucalyptus globulus in response to nitrogen concentrations in nutritive solution, in a fertirrigation system. To do so, we used five clones, namely: two of Eucalyptus urophylla x Eucalyptus globulus (C-04 and C-16); two of Eucalyptus grandis x Eucalyptus globulus (C-26 and C-30) and one of Eucalyptus urophylla $\mathrm{x}$ Eucalyptus grandis (1213) as a comparator. Five N concentrations were tested $\left(36,72,109,164\right.$ and $\left.218 \mathrm{mg} \mathrm{L}^{-1}\right)$ in a statistical design of randomized blocks on a split plot arrangement with three replications. Six months after the implementation, using standard nutritive solution, in fertirrigation system, the treatment application began.

1 Administrador, MSc., Departamento de Engenharia Florestal, Centro de Ciências Agrárias, Universidade Federal de Viçosa, Av. Peter Henry Rolfs, s/n, Campus Universitário, CEP 36570-000, Viçosa (MG), Brasil. alexffreitas@yahoo.com.br

2 Engenheiro Florestal, Dr., Professor Associado do Departamento de Engenharia Florestal, Centro de Ciências Agrárias, Universidade Federal de Viçosa, Av. Peter Henry Rolfs, s/n, Campus Universitário, CEP 36570-000, Viçosa (MG), Brasil. hnpaiva@ufv.br

3 Engenheiro Florestal, Dr., Professor Titular do Departamento de Engenharia Florestal, Centro de Ciências Agrárias, Universidade Federal de Viçosa, Av. Peter Henry Rolfs, s/n, Campus Universitário, CEP 36570-000, Viçosa (MG), Brasil.xavier@ufv.br

4 Engenheiro Agrônomo, Dr., Professor Associado do Departamento de Solos, Centro de Ciências Agrárias, Universidade Federal de Viçosa, Av. Peter Henry Rolfs, s/n, Campus Universitário, CEP 36570-000, Viçosa (MG), Brasil.julio_n2003@yahoo.com.br

Recebido para publicação em 19/12/2013 e aceito em 29/07/2015

Ci. Fl., v. 27, n. 1, jan.-mar., 2017 
After 30 days, it began the weekly harvest of minicuttings and the cutting plantion at every 15 days, during 90 days. It was evaluated the survival and the productivity of the ministumps and, regarding the minicuttings, it was observed: the survival, the rooting percentage, the minicutting percentage with visible roots at the lower end of the tube, having these $10 \mathrm{~cm}$, after 30 days in the greenhouse. It was found that there is a significant effect of $\mathrm{N}$ concentration over the monthly productivity of ministumps from clones $\mathrm{C}-16$ (169.05 $\left.\mathrm{mg} \mathrm{L}^{-1}\right), \mathrm{C}-26$ (146.67 $\mathrm{mg} \mathrm{L}^{-1}$ ) and for C-04 and 1213, (positive linear effect). However, no significant effect of dose was observed for the percentage of visible roots at the lower end of the tube, rooting and survival of cuttings at thirty days in the greenhouse.

Keywords: clonal minigarden; mineral nutrition; vegetative propagation.

\section{INTRODUÇÃO}

Dentre as várias espécies de Eucalyptus, uma tem despertado o interesse do segmento de celulose e papel brasileiro, o Eucalyptus globulus. Isto, em razão de possuir excelente rendimento em celulose, alta densidade da madeira, baixo teor de lignina e menor consumo de cloro no branqueamento (FONSECA et al., 2010). Estes autores ainda acreditam que o fato de ser uma espécie tipicamente de clima temperado, com certa restrição de adaptação às regiões com altas temperaturas e invernos secos, são alguns motivos para que não seja plantada em larga escala no Brasil, além de sua dificuldade no enraizamento, uma vez que é considerada recalcitrante à rizogênese (ALFENAS et al., 2009).

Neste sentido, Assis e Mafia (2007) afirmaram que a técnica de hibridação interespecífica é uma forma de contornar estes obstáculos através do desenvolvimento de materiais genéticos que conciliem qualidade da madeira, produtividade, competência rizogênica, além de adaptação às condições climáticas das regiões mais quentes do Brasil.

Os possíveis benefícios da utilização de genótipos híbridos de Eucalyptus globulus devem ser potencializados por técnicas economicamente viáveis para propagação destes indivíduos superiores. Assis, Fett-neto e Alfenas (2004) afirmaram que a propagação vegetativa é uma das mais importantes ferramentas para aumentar a competitividade da indústria, pois transforma os ganhos genéticos em benefícios, sendo esta técnica de grande relevância para a propagação massal das matrizes superiores. Cunha et al. (2008) complementam ao afirmar que o sucesso da produção de mudas via enraizamento adventício está relacionado ao conhecimento dos fatores que afetam a formação de raízes.

O manejo nutricional do minijardim clonal é apontado por Higashi, Silveira e Gonçalves (2002); Cunha et al. (2008); Alfenas et al. (2009) e Xavier, Wendling e Silva (2013) como um dos fatores de maior relevância na produção massal de propágulos vegetativos. Sendo o nitrogênio um dos nutrientes mais demandados pelas plantas, conhecer sua ação na produtividade das minicepas de diferentes clones híbridos de Eucalyptus globulus, bem como na formação de raízes adventícias, é fundamental para o sucesso deste processo de propagação que visa tornar o setor florestal brasileiro ainda mais competitivo no contexto global.

Higashi, Silveira e Gonçalves (2000) verificaram os efeitos das concentrações de nitrogênio na produção e no enraizamento de miniestacas de clones de Eucalyptus produzidas no sistema de minijardim clonal em leito de areia. Os resultados mostraram que houve interação entre as concentrações de $\mathrm{N}$ e os clones para percentagem de enraizamento, observando-se relação direta, para um dos clones, entre o aumento da concentração de $\mathrm{N}$ ministrada às minicepas e o percentual de enraizamento observado nas miniestacas.

Porém, Haissig (1986) observou que a deficiência de $\mathrm{N}$ mostrou efeito positivo no enraizamento de estacas de videira destacando que, geralmente, moderadas deficiências de nitrogênio são mais benéficas ao enraizamento do que excesso ou mesmo níveis adequados desse nutriente. Hartmann et al. (2011) também destacam que, geralmente, o enraizamento é negativamente correlacionado com o teor de $\mathrm{N}$.

Desta forma, objetivou-se avaliar a produtividade de minicepas e o enraizamento das miniestacas de híbridos de Eucalyptus globulus em resposta a concentrações de nitrogênio aplicadas em fertirrigação de minijardim clonal. 


\section{MATERIAL E MÉTODOS}

O experimento foi conduzido no Viveiro de Pesquisas do Departamento de Engenharia Florestal, localizado no campus da Universidade Federal de Viçosa, na cidade de Viçosa - Minas Gerais, no período de agosto de 2011 a junho de 2012.

Viçosa está situada na Zona da Mata Norte, latitude $20^{\circ} 45^{\prime} 20^{\prime \prime}$ e longitude $42^{\circ} 52^{\prime} 40^{\prime \prime}$, a 649 metros acima do nível do mar. O clima desta região é do tipo Cwb (verões chuvosos e invernos frios e secos) segundo a classificação de Köppen. A temperatura mínima média anual de $13,2^{\circ} \mathrm{C}$ e $25,6^{\circ} \mathrm{C}$, para a temperatura máxima. Umidade relativa do ar média de $80 \%$ e precipitação média de $1315 \mathrm{~mm} /$ ano (IBGE, 2010).

O efeito de cinco concentrações de nitrogênio $\left(36,72,109,164\right.$ e $\left.218 \mathrm{mg} \mathrm{L}^{-1}\right)$ em fertirrigação foi testado, sobre a produtividade de minicepas e enraizamento de miniestacas de cinco clones, sendo dois clones de Eucalyptus urophylla $x$ Eucalyptus globulus (C- 04 e C- 16), dois clones de Eucalyptus grandis $x$ Eucalyptus globulus (C-26 e C- 30) e um clone de Eucalyptus urophylla x Eucalyptus grandis (1213).

Adotou-se um arranjo de parcelas subdivididas no qual as parcelas eram as concentrações e as subparcelas os clones. Este arranjo foi disposto no delineamento estatístico de blocos ao acaso, em três repetições. Cada parcela foi constituída por 80 minicepas, sendo 16 de cada clone (subparcela).

O minijardim, em alvenaria, era fechado lateralmente com Clarite ${ }^{\circledR}$, com teto plástico fixo e piso cimentado. Cada um dos leitos do minijardim tinha $0,8 \times 15,6 \mathrm{~m}$ sendo que a cada 1,2 $\mathrm{m}$ de comprimento, constituía-se uma parcela. Estas foram cuidadosamente isoladas por placas de fibra e lona plástica, visando à diminuição da possibilidade de contaminação pela solução nutritiva aplicada nas parcelas vizinhas.

O sistema de irrigação adotado foi o gotejamento, utilizando quatro fitas de irrigação com gotejadores espaçados a cada $30 \mathrm{~cm}$, isto é, 16 gotejadores por parcela, bomba hidráulica de $0,5 \mathrm{cv}$ por tratamento.

Os reservatórios tinham capacidade efetiva de 140 litros de solução nutritiva, sendo que a vazão adotada na fertirrigação foi de $5 \mathrm{~L} / \mathrm{m}^{2} /$ dia. Este volume foi distribuído em cinco aplicações de três minutos, via sistema automatizado por timer digital, sendo realizadas às $9 \mathrm{~h}, 11 \mathrm{~h}, 13 \mathrm{~h}, 15 \mathrm{~h}$ e $17 \mathrm{~h}$.

Três semanas antes do plantio das mudas no minijardim foi realizada poda dos ápices, visando à perda de dominância apical e, em alguns casos, rebaixamento da cepa. Na semana que antecedeu o plantio foi aplicado fosfato monoamônio, à concentração de 1,5\%, $5 \mathrm{~mL}$ por tubete. As minicepas foram plantadas no minijardim clonal em agosto de 2011, no espaçamento $10 \times 10 \mathrm{~cm}$.

O manejo do minijardim consistiu em monitoramento integrado de pragas e doenças (MIPD), trocas das soluções nutritivas, monitoramento de produtividade e aferição de condutividade elétrica (CE) e potencial hidrogeniônico $(\mathrm{pH})$.

Aferições da $\mathrm{CE}$ e $\mathrm{pH}$ foram realizadas em média a cada duas semanas, com o auxílio de um condutivímetro e um pHmetro portátil, visando à manutenção do $\mathrm{pH}$ entre 5,5 a 6,5 e da CE entre 1,5 e $2,0 \mathrm{mS} \cdot \mathrm{cm}^{-1}$. O monitoramento do $\mathrm{pH}$ foi realizado nos recipientes de armazenamento das soluções nutritivas; já a CE foi monitorada no efluente de cada parcela. Quando necessário foi realizada correção individual, através de aplicação de água pura utilizando chuveiro de irrigação.

Durante o experimento foi necessária a utilização de fungicidas à base de triadimenol e tebucunazole, visando ao controle da ferrugem do eucalipto (Puccinia psidii), Quambalaria eucalypti e Cylindrocladium sp. Foi utilizado ainda deltametrina, para controlar a incidência da mosca-do-viveiro e pulgões. É importante ressaltar que o controle fitossanitário ocorreu sempre de modo curativo e utilizando todos os equipamentos de segurança necessários às aplicações seguindo recomendação de Alfenas et al. (2009).

Após a implantação das minicepas no minijardim, iniciou-se a fertirrigação visando homogeneizar o estado fisiológico na formação da copa antes do início da aplicação dos tratamentos; para tanto, utilizou-se uma solução nutritiva composta de nitrato de cálcio $\left(0,920 \mathrm{~g} \mathrm{~L}^{-1}\right)$, cloreto de potássio $\left(0,240 \mathrm{~g} \mathrm{~L}^{-1}\right)$, nitrato de potássio $\left(0,140 \mathrm{~g} \mathrm{~L}^{-1}\right)$, monoamônio fosfato $\left(0,096 \mathrm{~g} \mathrm{~L}^{-1}\right)$, sulfato de magnésio $\left(0,364 \mathrm{~g} \mathrm{~L}^{-1}\right)$, Ferrilene ${ }^{\circledR}\left(0,040 \mathrm{~g} \mathrm{~L}^{-1}\right)$, ácido bórico $\left(2,800 \mathrm{mg} \mathrm{L}^{-1}\right)$, sulfato de zinco $\left(0,480 \mathrm{mg} \mathrm{L}^{-1}\right)$, sulfato de manganês $\left(1,120 \mathrm{mg} \mathrm{L}^{-1}\right)$, sulfato de cobre $\left(0,100 \mathrm{mg} \mathrm{L}^{-1}\right)$ e molibdato de sódio $\left(0,040 \mathrm{mg} \mathrm{L}^{-1}\right)$. O intervalo de aplicação foi de agosto de 2011 a janeiro de 2012, data em que teve início a aplicação dos tratamentos. 
Tais sais e suas respectivas quantidades proporcionaram as seguintes concentrações para os

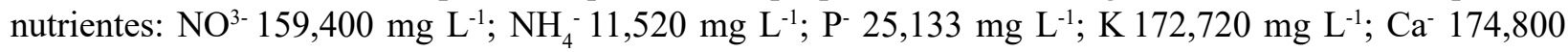
$\mathrm{mg} \mathrm{L}^{-1} ; \mathrm{Mg}^{-} 32,760 \mathrm{mg} \mathrm{L}^{-1} ; \mathrm{S}^{-} 43,628 \mathrm{mg} \mathrm{L}^{-1} ; \mathrm{B}^{-}$0,476 mg L-1 $\mathrm{Fe}^{-}$2,400 $\mathrm{mg} \mathrm{L}^{-1} ; \mathrm{Cu}^{-} 0,025 \mathrm{mg} \mathrm{L}^{-1}$; $\mathrm{Mn}^{-} 0,364 \mathrm{mg} \mathrm{L}^{-1} ; \mathrm{Zn}^{-} 0,096 \mathrm{mg} \mathrm{L}^{-1}$ e $\mathrm{Mo}^{-} 0,016 \mathrm{mg} \mathrm{L}^{-1}$.

Os tratamentos aplicados foram derivados de solução nutritiva utilizada em minijardim clonal, com leito de areia, de um viveiro comercial que apresenta as seguintes concentrações: $\mathrm{NO}_{3}{ }^{-}$

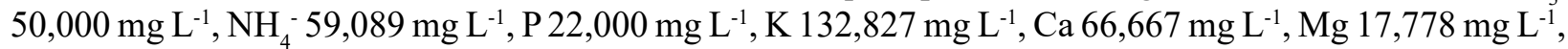
$\mathrm{S} 77,022 \mathrm{mg} \mathrm{L}^{-1}$, B 0,237 $\mathrm{mg} \mathrm{L}^{-1}$, Fe 1,933 $\mathrm{mg} \mathrm{L}^{-1}$, Cu 0,047 $\mathrm{mg} \mathrm{L}^{-1}$, Mn 0,241 $\mathrm{mg} \mathrm{L}^{-1}$, Zn 0,056 mg L-1 e Mo $0,015 \mathrm{mg} \mathrm{L}^{-1}$, a qual passou a ser considerada padrão, sendo a concentração de $\mathrm{N}$ utilizada considerada $100 \%$, ou testemunha, variando $33 \%, 66 \%, 150 \%$ e $200 \%$ desta concentração para os demais tratamentos. Testando, assim, as doses de 36; 72; 109; 164 e $218 \mathrm{mg} \mathrm{L}^{-1}$. Adotou-se a relação $1 / 1$ entre a concentração de nitrato e amônio, quando da seleção dos sais contendo nitrogênio.

A solução nutritiva comercial foi aplicada a partir de janeiro de 2012, sendo os tratamentos aplicados a partir de fevereiro de 2012. A sobrevivência e a produtividade das minicepas juntamente com o enraizamento das miniestacas foram avaliadas durante os meses de março, abril e maio de 2012.

Semanalmente eram feitas coletas das miniestacas produzidas visando quantificar a produtividade das minicepas. Quinzenalmente foi retirada uma amostra de 16 miniestacas/subparcela, visando avaliar a influência dos tratamentos no enraizamento e sobrevivência das miniestacas, ao final do período de casa de vegetação (trinta dias).

As miniestacas com 8 a $10 \mathrm{~cm}$ de comprimento, contendo dois ou três pares de folhas inteiras e o ápice sem redução foliar, antes e durante a coleta, receberam pulverização de água pura via pulverizador manual; posteriormente, foram transportadas para a casa de vegetação em caixas plásticas com tampas e estaqueadas em tubetes de polipropileno com volume de 54,0 $\mathrm{cm}^{3}$, dispostos em grades de 96 unidades.

Estas embalagens juntamente com os suportes foram desinfestados através de imersão em água a $70^{\circ} \mathrm{C}$ por 3 minutos, como recomendado por Alfenas et al. (2009) e preenchidos através de mesa compactadora com substrato comercial, formado pela mistura de composto de casca de pinus, vermiculita com granulometria média, fibra de coco e casca de arroz carbonizada. A adubação de base utilizada foi composta de superfosfato simples $\left(6,00 \mathrm{~kg} / \mathrm{m}^{3}\right)$.

A casa de vegetação era automatizada, possuindo sistema de irrigação via nebulização e janela zenital para controle da umidade mínima superior a $80 \%$ e a temperatura inferior a $30^{\circ} \mathrm{C}$. Tal estrutura também contava com bancadas de alvenaria e piso cimentado.

As amostras de miniestacas retiradas durante o monitoramento de produtividade foram estaqueadas seguindo a mesma casualização do minijardim clonal. Cada grade continha dezesseis miniestacas de cada clone, representando as cinco subparcelas por parcela.

Após trinta dias em casa de vegetação, foram avaliadas as percentagens de sobrevivência (\%SOB), formação de raízes visíveis na extremidade inferior do tubete (\%REIT) e enraizamento (\%ENR).

Para efeito das avaliações, foram consideradas enraizadas as miniestacas com raízes maiores ou iguais a $0,5 \mathrm{~cm}$ e sobreviventes aquelas com coloração verde e emissão de brotações.

Como foi utilizado o delineamento blocos ao acaso, no arranjo parcelas subdivididas, o efeito de concentração dentro de cada clone foi avaliado mediante equações de regressão selecionadas com base na significância dos coeficientes considerados, quadrado médio do resíduo combinado pela fórmula de Satterhwaite (1949), citado por Stell, Torre e Dickey (1997), e respectivos números de graus de liberdade e ainda nos valores de $\mathrm{R}^{2}$. As análises de regressão foram realizadas em nível de 1,5 e $10 \%$ de probabilidade, utilizando o programa Statistica versão 7.0. Para verificar o efeito de N sobre clone foi aplicado o Teste de Tukey, a $5 \%$ de probabilidade.

\section{RESULTADOS E DISCUSSÃO}

Após três meses de monitoramento, com colheitas semanais no minijardim clonal e estaqueamentos quinzenais, verificou-se efeito significativo dos clones e concentrações de nitrogênio.

Durante a condução do experimento, não foram observados sintomas de deficiência e toxidez de $\mathrm{N}$ nas minicepas avaliadas e não houve mortalidade das mesmas. Verificou-se a existência de efeito 
significativo das concentrações de nitrogênio na produtividade mensal das minicepas dos clones C-04; C-16; C-26 e 1213. Entretanto, não foi observado efeito significativo das concentrações para a percentagem de miniestacas com raízes visíveis na extremidade inferior do tubete, enraizamento e sobrevivência das miniestacas aos trinta dias posteriores à coleta.

O percentual de sobrevivência (\%SOB) dos propágulos não foi influenciado pelas concentrações de nitrogênio aplicadas à solução nutritiva (Tabela 1). Verificou-se também que todos os clones testados não diferiram estatisticamente, pelo teste Tukey $(\mathrm{p}=0,05)$, quando analisados em uma mesma concentração, indicando que tal variável, tende a não estar vinculada a concentrações de $\mathrm{N}$ ou genótipo.

Altas taxas de sobrevivência das miniestacas foram, também, descritas por Borges et al. (2011) e Oliveira et al. (2012), ambos trabalhando com genótipos híbridos de Eucalyptus globulus, utilizando concentração de nitrogênio igual a $170 \mathrm{mg} \mathrm{L}^{-1}$. Estes autores apresentaram valores médios de 91 e $86 \%$ de sobrevivência, respectivamente, sendo os resultados encontrados neste trabalho iguais ou superiores às médias dos autores supracitados.

$\mathrm{Na}$ literatura constam percentuais de sobrevivência menores, como $83 \%$ para miniestacas de três clones de Eucalyptus benthamii x Eucalyptus dunnii (BRONDANI et al., 2010), 73\% em miniestacas seminais de Eucalyptus dunnii (ROSA et al., 2009) e ainda 55\% de sobrevivência para miniestacas de Eucalyptus globulus x Eucalyptus maidenii (PAIM et al., 2005).

Em relação à produtividade das minicepas, verificou-se que $80 \%$ dos genótipos testados apresentaram resultados significativos para as concentrações aplicadas (Figura 1). Observam-se respostas distintas, dentre os clones avaliados, indicando que a demanda por nitrogênio para a produtividade das cepas foi genótipo dependente (Tabela 2); concordando com o resultado encontrado por Cunha et al. (2008), trabalhando em minijardim clonal com vários clones de eucalipto.

$\mathrm{O}$ único clone que não apresentou resposta significativa para as diferentes concentrações de $\mathrm{N}$ na produtividade de suas minicepas foi o C-30 (Eucalyptus grandis x Eucalyptus globulus). Os materiais C-04 e 1213 tiveram respostas lineares positivas (Figura 1), indicando a necessidade de se avaliarem concentrações mais elevadas para obtenção de produtividades ainda maiores.

Rosa et al. (2009), trabalhando com minicepas seminais de Eucalyptus dunnii, alcançaram resultados semelhantes, uma vez que também não atingiram o ponto de máxima produção em função da aplicação de nitrogênio, mas verificaram que a maior concentração aplicada $\left(600 \mathrm{mg} \mathrm{L}^{-1}\right)$ promoveu a maior produtividade $(8,86$ miniestacas por minicepa por mês). Estes autores consideraram natural a produtividade ser diretamente proporcional à concentração de $\mathrm{N}$ na solução nutritiva, uma vez que o nitrogênio está vinculado a todas as atividades metabólicas; porém, enfatizaram a existência do nível ótimo, a partir do qual

TABELA 1: Percentagem de sobrevivência de miniestacas de quatro clones híbridos de Eucalyptus globulus (C-04, C-16, C-26 e C-30) e um de Eucalyptus urophylla x Eucalyptus grandis (1213), após 30 dias de casa de vegetação, em função das concentrações de $\mathrm{N}\left(\mathrm{mg} \mathrm{L}^{-1}\right)$, aplicadas em solução nutritiva no minijardim clonal.

TABLE 1: Percentage survival of cuttings of four hybrid clones of Eucalyptus globulus (C-04, C-16, C-26 e C-30) and Eucalyptus urophylla $\mathrm{x}$ Eucalyptus grandis (1213), after 30 days in the greenhouse, by concentrations of $\mathrm{N}\left(\mathrm{mg} \mathrm{L}^{-1}\right)$ applied in nutrient solution on the clonal minigarden.

\begin{tabular}{cccccc}
\hline \multicolumn{5}{c}{ Sobrevivência } \\
\hline \multirow{2}{*}{ Clones } & 36 & 72 & 109 & 164 & 218 \\
\cline { 2 - 6 } & 94,79 & 95,14 & 94,10 & 96,88 & 95,14 \\
C-04 & 90,97 & 92,71 & 88,19 & 93,40 & 92,36 \\
C-16 & 91,32 & 91,67 & 93,75 & 95,49 & 95,49 \\
C-26 & 90,28 & 89,58 & 92,36 & 92,36 & 93,75 \\
C-30 & 96,18 & 95,49 & 90,63 & 94,44 & 95,49 \\
\hline 1213 & 92,71 & 92,92 & 91,81 & 94,51 & 94,44 \\
\hline Média & & & & & \\
\hline
\end{tabular}


TABELA 2: Médias da produtividade de minicepas de quatro clones híbridos de Eucalyptus globulus (C-04, C-16, C-26 e C-30) e um de Eucalyptus urophylla x Eucalyptus grandis (1213), durante 90 dias de monitoramento, em função de concentrações de $\mathrm{N}\left(\mathrm{mg} \mathrm{L}^{-1}\right)$, aplicadas em solução nutritiva no minijardim clonal.

TABLE 2: Average productivity of ministumps of hybrids of Eucalyptus globulus (C-04, C-16, C-26 e C-30) and Eucalyptus urophylla $\mathrm{x}$ Eucalyptus grandis (1213), during 90 days of monitoring, depending on the concentrations of $\mathrm{N}\left(\mathrm{mg} \mathrm{L}^{-1}\right)$ applied in nutrient solution on the clonal minigarden.

\begin{tabular}{cccccc}
\hline \multicolumn{5}{c}{ Miniestacas/minicepa/mês } \\
\hline \multirow{2}{*}{ Clones } & 36 & 72 & 109 & 164 & 218 \\
\cline { 2 - 6 } & $7,45 \mathrm{ab}$ & $8,04 \mathrm{a}$ & $8,63 \mathrm{a}$ & $8,22 \mathrm{ab}$ & $8,50 \mathrm{a}$ \\
C-04 & $6,41 \mathrm{bc}$ & $7,51 \mathrm{a}$ & $7,76 \mathrm{ab}$ & $8,05 \mathrm{abc}$ & $7,98 \mathrm{ab}$ \\
$\mathrm{C}-16$ & $5,71 \mathrm{c}$ & $6,71 \mathrm{a}$ & $7,00 \mathrm{~b}$ & $6,79 \mathrm{c}$ & $6,91 \mathrm{~b}$ \\
C-26 & $6,47 \mathrm{abc}$ & $6,77 \mathrm{a}$ & $7,49 \mathrm{ab}$ & $7,17 \mathrm{bc}$ & $7,01 \mathrm{~b}$ \\
C-30 & $7,72 \mathrm{a}$ & $8,19 \mathrm{a}$ & $8,66 \mathrm{a}$ & $8,99 \mathrm{a}$ & $8,75 \mathrm{a}$ \\
1213 & 6,75 & 7,44 & 7,91 & 7,84 & 7,83 \\
\hline Média & 5 &
\end{tabular}

Em que: Médias seguidas de uma mesma letra na coluna não diferem pelo teste Tukey $(\mathrm{p}=0,05)$.

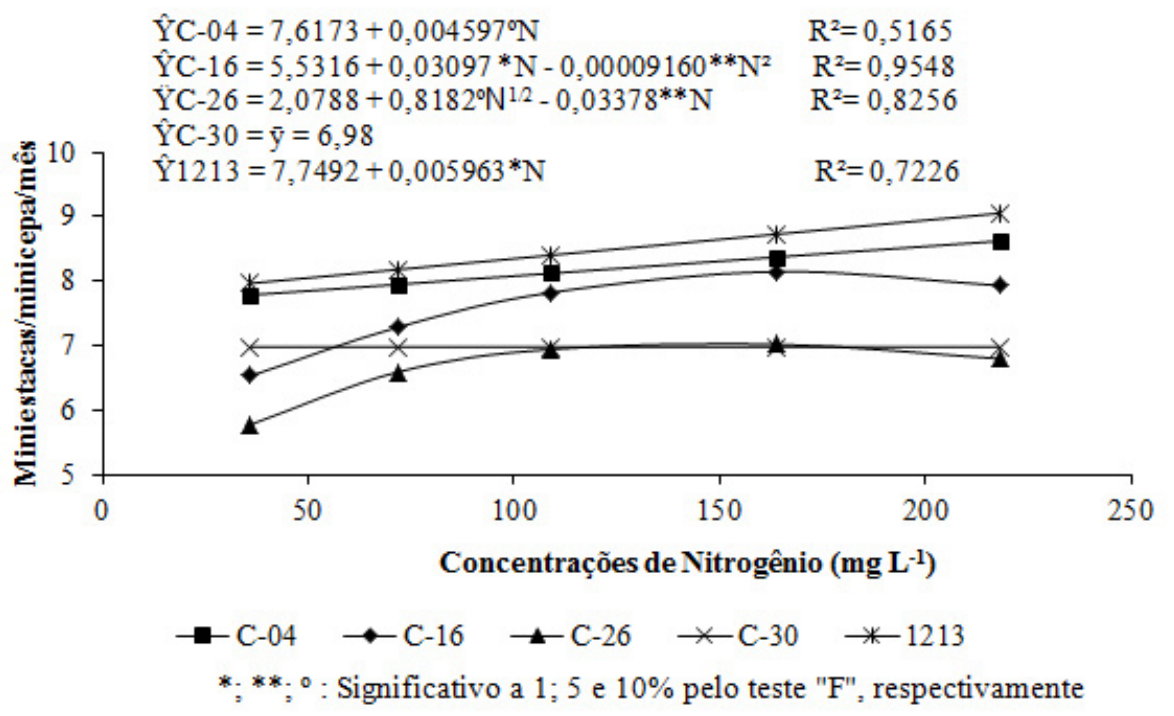

FIGURA 1: Produtividade de minicepas de quatro clones híbridos de Eucalyptus globulus (C-04, C-16, C-26 e C-30) e um de Eucalyptus urophylla x Eucalyptus grandis (1213), após 30 dias em casa de vegetação, em função de concentrações de $\mathrm{N}$, aplicadas em solução nutritiva no minijardim clonal.

FIGURE 1: Productivity ministumps four hybrid clones of Eucalyptus globulus (C-04, C-16, C-26 e C-30) and Eucalyptus urophylla $\mathrm{x}$ Eucalyptus grandis (1213), after 30 days in the greenhouse, depending on the concentration of $\mathrm{N}$ applied in nutrient solution on the clonal minigarden.

a planta exibe resultados indesejáveis ao aumento da concentração, podendo regredir a produção ou mesmo levar à morte das minicepas.

Os clones C-16 e C-26 alcançaram seus níveis ótimos de nitrogênio para produtividade, obtendo respostas quadráticas. Isto indica que houve uma resposta positiva elevando a produção da minicepa à medida que a concentração de $\mathrm{N}$ foi aumentada na solução nutritiva, mas posterior à determinada concentração, a resposta à fertilização passou a decrescer na medida em que a concentração de $\mathrm{N}$ foi aumentada. Para 
o clone C-16 a maior produtividade, 8,15 miniestacas/minicepa/mês, foi alcançada com a concentração de $169,05 \mathrm{mg} \mathrm{L}^{-1}$ em solução nutritiva; já para o clone C-26 verificou-se produtividade máxima de 7,03 miniestacas/minicepa/mês na concentração de $146,67 \mathrm{mg} \mathrm{L}^{-1}$ (Figura 1).

Ambas as concentrações estão contidas no intervalo recomendado por Higashi, Silveira e Gonçalves (2000) e Silveira e Higashi (1998) referenciados por Higashi, Silveira e Gonçalves (2000) de 100 a $200 \mathrm{mg} \mathrm{L}^{-1}$. Outros autores, como Brondani et al. (2010), Borges et al. (2011) e Oliveira et al. (2012) também utilizaram concentrações contidas nesta faixa de recomendação, aplicando 170; 170 e $129 \mathrm{mg} \mathrm{L}^{-1}$, respectivamente. Outros autores, como Rosa et al. (2009), utilizaram concentração próxima a $600 \mathrm{mg} \mathrm{L}^{-1}$.

Analisando a Tabela 2, que expõe a influência das diferentes concentrações de $\mathrm{N}$ entre os clones avaliados, verifica-se que o C-04 obteve resultados positivos, sendo estatisticamente igual ao clone 1213. Porém, o clone C-26 obteve, numericamente, produtividade sempre inferior aos demais genótipos, demonstrando sua menor eficiência produtiva, o que também pode ser observado na Figura 1.

Quanto à produtividade máxima individual verificada através do cálculo com a concentração ótima, determinada pelos modelos estatísticos ajustados (Figura 1), conclui-se que os valores para os clones híbridos de Eucalyptus globulus, C-04, C-16 e C-26, que foram 8,62; 8,15 e 7,03 miniestacas/ minicepa/mês respectivamente, superaram a produtividade de clones "puros" de Eucalyptus globulus, da empresa Mundial Florestación ${ }^{\circledR}$, em 2003. Segundo Alfenas et al. (2009), estes tinham produtividade média de 7488 miniestacas $/ \mathrm{m}^{2} /$ ano, em espaçamento de $0,08 \times 0,08 \mathrm{~m},\left(156,25\right.$ minicepas $\left./ \mathrm{m}^{2}\right)$; convertendo-se para a unidade miniestacas/minicepa/mês, tem-se 3,99 miniestacas, valor correspondente a pouco mais que $55 \%$ da menor produtividade alcançada. O que demonstra a superioridade dos clones híbridos de Eucalyptus globulus e/ou a eficiência do manejo nutricional das minicepas.

Outros valores médios relatados para produtividade de minicepas implantadas em minijardim clonal com leito de areia e fertirrigação por gotejamento, foram: 8,1 miniestacas/mês para minicepas seminais de Eucalyptus benthamii (CUNHA; WENDLING; SOUZA-JÚNIOR, 2005) e 12,6 para clones híbridos de Eucalyptus urophylla x Eucalyptus grandis (SOUZA, 2012). Já Cunha et al. (2008) e Cunha et al. (2009), trabalhando com informações do operacional de um empresa florestal referentes aos anos 2003 a 2005, relataram produtividades médias mensais por minicepa em híbridos de Eucalyptus urophylla $\mathrm{x}$ Eucalyptus grandis que variaram de 7,9 a 11,8 e 9,6 a 13,2, respectivamente.

Alfenas et al. (2009) também relataram informações de produtividade do operacional de algumas empresas florestais brasileiras referentes a 2003 que, se convertidas para produtividade mensal das minicepas, tem-se: 12,4 (Cenibra S.A.); 10,0 (Aracruz Celulose S.A. e VCP Florestal S.A.); 9,0 (CAF Florestal S.A.) e 8,1 (Suzano Bahia Sul S.A.), obtendo-se média geral de 9,9 miniestacas/minicepa/mês. Estes valores demonstram a adequação do manejo aplicado ao minijardim clonal e boa produtividade alcançada com o clone 1213 (referência), 9,05 miniestacas/minicepa/mês.

Cunha et al. (2008) já haviam recomendado o aumento da concentração de N na solução nutritiva para maior produção de brotos de clones de Eucalyptus urophylla x Eucalyptus grandis. Estes autores relacionaram o efeito positivo do nitrogênio ao aumento do número de miniestacas produzidas devido ao fato deste nutriente ser responsável pelo crescimento vegetativo.

$\mathrm{O}$ aumento de produtividade do minijardim clonal, almejado por todos os viveiros, somente é considerado adequado quando, além de produtividade da minicepa, tem-se sucesso na formação de raízes com elevadas percentagens de enraizamento e, consequentemente, altos índices de produtividade do viveiro.

A concentração ótima de $\mathrm{N}$ para produtividade de brotos independe do clone, e pode ser utilizada sem nenhuma perda no processo de enraizamento, já que as concentrações testadas de nitrogênio não influenciaram significativamente a variável enraizamento. Os resultados apontam uma margem elevada de segurança para flutuação da concentração deste nutriente na solução nutritiva, uma vez que ocorreram altos índices de enraizamento dentre as concentrações (Tabela 3) e houve ausência de sintomas de deficiência e toxidez nas minicepas e miniestacas.

Resultados contrários ao observado foram descritos por Schawambach, Fadanelli e Fett-neto (2005) e Rosa (2006) e revelam a influência do nitrogênio na porcentagem de microestacas enraizadas de Eucalyptus globulus (in vitro) e no enraizamento de miniestacas oriundas de minicepas seminais de Eucalyptus dunnii, respectivamente. 
TABELA 3: Percentagem de enraizamento das miniestacas de quatro clones híbridos de Eucalyptus globulus (C-04, C-16, C-26 e C-30) e um de Eucalyptus urophylla x Eucalyptus grandis (1213), após 30 dias em casa de vegetação, em função de concentrações de $\mathrm{N}\left(\mathrm{mg} \mathrm{L}^{-1}\right)$, aplicadas em solução nutritiva no minijardim clonal.

TABLE 3: Percentage of rooting of the minicuttings of four hybrid clones of Eucalyptus globulus (C-04, C-16, C-26 e C-30) and Eucalyptus urophylla x Eucalyptus grandis (reference), after 30 days in the greenhouse, depending on the concentrations of $\mathrm{N}\left(\mathrm{mg} \mathrm{L}^{-1}\right)$ applied in nutrient solution on the clonal minigarden.

\begin{tabular}{lccccc}
\hline \multicolumn{5}{c}{ Enraizamento de miniestacas (\%) } \\
\hline \multirow{2}{*}{ Clones } & 36 & 72 & 109 & 164 & 218 \\
\cline { 2 - 6 } & 84,38 & 83,33 & 79,86 & 83,68 & 87,50 \\
C-04 & 78,82 & 85,76 & 76,39 & 85,07 & 83,33 \\
C-16 & 81,25 & 87,15 & 85,76 & 90,28 & 87,50 \\
C-26 & 83,33 & 79,51 & 85,07 & 85,42 & 86,11 \\
C-30 & 87,15 & 86,11 & 81,60 & 83,68 & 85,07 \\
1213 & 82,99 & 84,38 & 81,74 & 85,63 & 85,90 \\
\hline \multicolumn{1}{c}{ Média } & & & & & \\
\hline
\end{tabular}

Ao analisar a Tabela 3, verifica-se que os genótipos híbridos de Eucalyptus globulus não diferiram estatisticamente do clone 1213 para enraizamento. Os valores são superiores aos relatados por Oliveira et al. (2012), que obtiveram percentagens de enraizamento de 78,1; 65,6; 78,1 e 75,0\% para os clones C-04; C-16; C-26 e C-30, respectivamente. Já Borges et al. (2011), trabalhando também com clones híbridos de Eucalyptus globulus, verificaram grande flutuação nestes valores, obtendo percentagens de 58,3 a 100\% de enraizamento. É importante ressaltar que os valores relatados por ambos os autores são oriundos de estacas apicais, sem aplicação do regulador de crescimento AIB e com redução foliar.

Souza (2012), trabalhando com clones de Eucalyptus urophylla $\mathrm{x}$ Eucalyptus grandis e miniestacas de $10 \mathrm{~cm}$ sem redução foliar, obteve resultados que flutuaram entre 70,3 e 93,8\% de enraizamento. Já Cunha et al. (2009), utilizando clones com mesma hibridação, descreveram valores de enraizamento de 71,9 a $86,5 \%$, tendo o clone 1213 alcançado $76,5 \%$, mais de $8 \%$ inferior à média geral entre as concentrações testadas, $84,72 \%$ (Tabela 3 ).

Apesar da impossibilidade de estabelecer um modelo estatístico que represente a população de cada um dos clones testados, a análise da média geral dos mesmos em uma mesma concentração (Tabela 4) permite observar o benefício de concentrações crescentes de $\mathrm{N}$ para a percentagem de REIT.

O percentual de REIT é um critério prático utilizado pelos viveiros florestais como indicativo do momento de retirada das miniestacas da casa de vegetação, identificando aquelas enraizadas e aptas a serem transferidas para a estrutura de sombreamento (BORGES et al., 2011; SOUZA, 2012). Desta forma, mecanismos que auxiliem na aceleração do processo de crescimento das raízes adventícias estarão otimizando o uso da casa de vegetação e, consequentemente, aumentando a produtividade do viveiro.

Ciente desta informação e analisando a Tabela 4, pode-se observar que as concentrações de $\mathrm{N}$ que estiverem contidas entre 36 e $218 \mathrm{mg} \mathrm{L}^{-1}$ de solução nutritiva tendem a não influenciar na otimização da casa de vegetação; por outro lado, permitem maior tranquilidade na determinação da concentração de nitrogênio a ser utilizada na solução nutritiva.

Um exemplo citado na bibliografia que pode embasar tal afirmação são os resultados obtidos por Oliveira et al. (2012) que, utilizando concentração de $170 \mathrm{mg} \mathrm{L}^{-1} \mathrm{e} 35$ dias de casa de vegetação, relataram 12,50; 25,00; 9,38 e 6,25\% de REIT para os clones C-04; C-16; C-26 e C-30, respectivamente.

\section{CONCLUSÕES}

O nitrogênio influencia positivamente a produtividade das minicepas de $80 \%$ dos clones de 
TABELA 4: Percentagem de raízes visíveis na extremidade inferior do tubete - REIT das miniestacas de clones híbridos de Eucalyptus globulus (C-04, C-16, C-26 e C-30) e um de Eucalyptus urophylla x Eucalyptus grandis (1213), após 30 dias de casa de vegetação, em função de concentrações de $\mathrm{N}\left(\mathrm{mg} \mathrm{L}^{-1}\right)$, aplicadas em solução nutritiva no minijardim clonal.

TABLE 4: Percentage of visible roots at the lower end of the tube - REIT minicutting four hybrid clones of Eucalyptus globulus (C-04, C-16, C-26 e C-30) and Eucalyptus urophylla x Eucalyptus grandis (1213), after 30 days in the greenhouse, depending on the concentrations of $\mathrm{N}\left(\mathrm{mg} \mathrm{L}^{-1}\right)$ applied in nutrient solution on the clonal minigarden.

\begin{tabular}{cccccc}
\hline \multicolumn{5}{c}{ Percentagem de miniestacas com raízes visíveis } \\
\hline \multirow{2}{*}{ Clones } & \multicolumn{5}{c}{ Concentrações de N $\left(\mathrm{mg} \mathrm{L}^{-1}\right)$} \\
\cline { 2 - 6 } & 36 & 72 & 109 & 164 & 218 \\
\hline C-04 & 62,77 & 56,72 & 60,18 & $63,92 \mathrm{a}$ & 68,57 \\
C-16 & 64,08 & 72,50 & 66,33 & $68,10 \mathrm{a}$ & 71,35 \\
C-26 & 69,59 & 69,37 & 64,76 & $71,56 \mathrm{a}$ & 71,07 \\
C-30 & 61,08 & 58,33 & 68,45 & 63,29 & 65,41 \\
1213 & 69,28 & 70,64 & 69,00 & 70,63 & 73,64 \\
\hline Média & 65,36 & 65,51 & 65,75 & 67,50 & 70,01 \\
\hline
\end{tabular}

Eucalyptus spp. testados, sendo que para os clones C-04 e 1213 esta variável respondeu de forma diretamente proporcional às concentrações testadas. Já para os clones C-16 e C-26, as concentrações ótimas são 169,05 e $146,67 \mathrm{mg} \mathrm{L}^{-1}$ respectivamente.

O enraizamento, a percentagem de raízes visíveis na extremidade inferior do tubete, a sobrevivência das miniestacas e das minicepas não são influenciados pelas concentrações de nitrogênio testadas na solução nutritiva para nenhum dos clones.

\section{AGRADECIMENTOS}

Os autores agradecem à FAPEMIG, por meio do projeto APQ 01018-09, pelo apoio financeiro, e ao CNPq pela concessão de bolsas de estudos e de produtividade em pesquisa.

\section{REFERÊNCIAS}

ALFENAS, A. C. et al. Clonagem e doenças do eucalipto. 2. ed. Viçosa: Editora UFV, 2009. 500 p. ASSIS, T. F.; FETT-NETO, A. G.; ALFENAS, A. C. Current techniques and prospects for the clonal propagation of hardwood with emphasis on Eucalyptus. In: WALTER, C.; CARSON, M. Plantation forest biotechnology for the 21th century. New Delhi: Research Sign Post, 2004. v. 1, p. 303-333.

ALFENAS, A. C. et al.; MAFIA, R. G. Hibridação e clonagem. In: BORÉM, A. (Ed.). Biotecnologia Florestal. Viçosa: [s.n.], 2007. p. 93-121.

BORGES, S. R. et al. Enraizamento de miniestacas de clones híbridos de Eucalyptus globulus. Revista Árvore, Viçosa, MG, v. 35, n. 3, p. 425-434, 2011.

BRONDANI, G. E. et al. Miniestaquia de Eucalyptus benthamii $\times$ Eucalyptus dunnii: (II) Sobrevivência e enraizamento de miniestacas em função das coletas e estações do ano. Ciência Florestal, Santa Maria, v. 20, n. 3 , p. $453-465,2010$.

CUNHA, A. C. M. C. M. et al. Relação do estado nutricional de minicepas com o número de miniestacas de eucalipto. Scientia Forestais, Piracicaba, v. 36, n. 79, p. 203-213, 2008.

CUNHA, A. C. M. C. M. et al. Relação do estado nutricional de minicepas com o enraizamento de miniestacas de eucalipto. Revista Brasileira de Ciência do Solo, Viçosa, MG, v. 33, p. 591-599, 2009.

CUNHA, A. C. M. C. M. et al. ; WENDLING, I.; SOUZA-JÚNIOR, L. Produtividade e sobrevivência de 
minicepas de Eucalyptus benthamii Maiden et Cambage em sistema de hidroponia e em tubetes. Ciência Florestal, Santa Maria, v. 15, n. 3, p. 307-310, 2005.

FONSECA, S. M. et al. Manual prático de melhoramento genético do eucalipto. Viçosa: Editora UFV, 2010. 200 p.

HAISSIG, B. E. Metabolic processes in adventitious rooting of cuttings. In: JACKSON, M. B. New root formation in plants and cuttings. Dordrecht: Martinus Nijhoff, 1986. p. 141-189.

HARTMANN, H. T. et al. Plant propagation: principles and pratices. 7. ed. New Jersey: Prentice-Hall, 2011.

HIGASHI, E. N.; SILVEIRA, R. L. V. A.; GONÇALVES, A. N. Monitoramento nutricional e fertilização em macro, mini e microjardim clonal de Eucalyptus. In: GONÇALVES, J. L. M.; BENEDETTI, V. (Eds.). Nutrição e fertilização florestal. Piracicaba: IPEF, 2000. p. 191-217.

HIGASHI, E. N.; SILVEIRA, R. L. V. A.; GONÇALVES, A. N. Nutrição e adubação em minijardim clonal hidropônico de Eucalyptus. Piracicaba: IPEF, 2002. 24 p.

IBGE. [Site institucional]. 2010. Disponível em: $<$ http://www.ibge.gov.br/cidadesat/317130>. Acesso em: 12 jul. 2012.

OLIVEIRA, L. S. et al. Enraizamento de miniestacas e microestacas de clones de Eucalyptus urophylla x E. globulus e de Eucalyptus grandis x E. globulus. Scientia Forestalis, Piracicaba, v. 40, n. 96, p. 507-516, 2012.

PAIM, D. C. et al. Physiological characterization of adventitious rooting in Eucalyptus globulus $\mathrm{x}$ E. maidenii minicuttings. In: CONGRESSO BRASILEIRO DE FISIOLOGIA VEGETAL, 10., 2005, Recife. Anais... Campinas: SBFV, 2005, p. 34-37.

ROSA, L. S. Adubação nitrogenada e substratos na miniestaquia de Eucalyptus dunnii Maiden. 2006. 89 f. Dissertação (Mestrado em Engenharia Florestal) - Setor de Ciências Agrárias, Universidade Federal do Paraná, Curitiba, PR, 2006.

ROSA, L. S. et al. Efeito da dose de nitrogênio e de formações de substratos na miniestaquia de Eucalyptus dunnii Maiden. Revista Árvore, Viçosa, MG, v. 33, n. 6, p. 1025-1035, 2009.

SCHAWAMBACH, J.; FADANELLI, C.; FETT-NETO, A. G. Mineral nutrition and adventitious rooting in microcuttings of Eucalyptus globulus. Tree Physiology, New York, v. 25, p. 487-494, 2005.

SOUZA, C. C. Padrões de miniestacas e densidade de minicepas na propagação clonal de Eucalyptus grandis x E. urophylla. 2012, 57 f. Dissertação (Mestrado em Ciência Florestal) - Universidade Federal de Viçosa, Viçosa, 2012.

STEEL, R. G. D.; TORRE, J. H.; DICKEY D. A. Principles and procedures of statics: a biometrical approach. 3. ed. New York: McGraw Hill, 1997. 666 p.

XAVIER A.; WENDLING, I.; SILVA, R. L. Silvicultura clonal: princípios e técnicas. 2. ed. Viçosa: Editora UFV, 2013. $278 \mathrm{p}$. 